\title{
Clinical audit and the purchaser-provider interaction: different attitudes and expectations in the United Kingdom
}

\author{
Richard Thomson, Catherine Elcoat, Edwin Pugh
}

\begin{abstract}
Objectives-To explore and describe the views on clinical audit of healthcare purchasers and providers, and in particular the interaction between them, and hence to help the future development of an appropriate interaction between purchasers and providers.

Design-Semistructured interviews.

Setting-Four purchaser and provider pairings in the former Northern Region of the National Health Service (NHS) in England.
\end{abstract}

Subjects-Chief executives, contracts managers, quality and audit leaders, directors of public health, consultants, general practitioners, audit support staff, and practice managers (total 42).

Main measures-Attitudes on the present state and future development of clinical audit.

Results-Purchasers and providers shared common views on the purpose of clinical audit, but there were important differences in their views on the level and appropriateness of involvement of health care purchasers, integration with present NHS structures and processes (including contracting and the internal market), priority setting for clinical audit, the effects of clinical audit on service development and purchasing, change in behaviour, and the sharing of information on the outcomes of clinical audit.

Conclusions-There are important differences in attitudes towards, and expectations of, clinical audit between health care purchasers and providers, at least in part due to the limited contact between them on audit to date. The nature of the relation and dialogue between purchasers and providers will be critical in determining whether clinical audit meets the differing aspirations of both groups, while achieving the ultimate goal of improving the quality of patient care.

(Quality in Health Care 1996;5:97-103)

Keywords: audit, purchaser, interview survey

\section{Introduction}

The National Health Service (NHS) reforms in the United Kingdom established competition through the introduction of the internal market and the creation of separate healthcare purchasers and providers. ${ }^{1}$ Health authorities and some general practices (commissioning health authorities and general practice fundholders) could begin to influence the quality of care by purchasing services and specifying standards in contracts with hospitals and community health services. ${ }^{2-4}$ A key feature associated with the reforms was a drive for widespread adoption of professional audit (initially medical and later including nursing and therapy audit), ${ }^{5}$ although this was initially professionally led and not incorporated within the purchaser-provider interaction and contracting.

Recently there has been a requirement to develop multidisciplinary audit and incorporate purchasers' interests in the process. ${ }^{6-8}$ Concerns have been expressed about the implications of purchaser involvement for the future development of clinical audit, although others think that audit can only achieve its potential when purchasers' interests are incorporated into the processes in line with the reforms (box 1). ${ }^{9-11}$ No formal study has attempted to consider linked purchasers' and providers' views on clinical audit, although provider, managerial, and clinical attitudes have been explored, ${ }^{9} 1012$ and CASPE have surveyed both purchasers and providers separately in the United Kingdom. ${ }^{13} 14$ This study explored the views of key people within health authority and general practice purchasers, and associated hospital and community health services to: (a) identify and clarify the perceptions of audit held by purchasers and providers in terms of definition,

- Medical audit and recently clinical audit were introduced after the recent reforms as a requirement of clinical staff in the United Kingdom NHS

- The NHS reforms also led to the development of the purchaser-provider separation and the creation of an internal market in health care

- Hospitals and community health services were able to become independent trusts, contracting for services with purchasers (health authorities and general practice fundholders)

- Initially specific funding was made available to support the development of programmes of audit (professionally led quality assurance) and distributed to providers

- Subsequently, funds for audit have been included in the overall allocation to purchasers of health care, giving them greater influence on the content and development of audit in secondary and tertiary care

Box 1 The relation between purchasers, providers, and audit 


\begin{tabular}{|c|c|c|c|}
\hline \multicolumn{2}{|l|}{$\begin{array}{l}\text { Purchaser (health authority } \\
\text { of GP fundholder) }\end{array}$} & \multicolumn{2}{|c|}{$\begin{array}{l}\text { Provider (hospital and } \\
\text { community health services) }\end{array}$} \\
\hline Chief executive & 3 & Chief executive & 4 \\
\hline Contracts manager & 4 & Contracts manager & 3 \\
\hline Quality leader/nurse & 4 & Quality leader/nurse & 4 \\
\hline Director of public health & 4 & Chair of audit committee & 3 \\
\hline Fundholding practice manager & 1 & Medical consultant & 3 \\
\hline Fundholding general practitioner & 5 & Audit support staff & 4 \\
\hline Total & 21 & Total & 21 \\
\hline
\end{tabular}

Box 2 The roles held by those interviewed

purpose, progress, and expectation: (b) explore the impact of the internal healthcare market on audit and identify views about the involvement of purchasers in the audit process; $(c)$ seek examples of collaborative working practices on audit between purchasers and providers; $(d)$ explore how and what information on audit should be shared between purchasers and providers; (e) explore the integration of audit into the contracting process within the internal healthcare market; $(f)$ identify the expectations held by purchasers and providers about the future funding of audit; $(g)$ and identify the critical factors which would assist purchasers and providers to maximise the opportunity represented by audit, to ensure that the care and services provided to healthcare consumers are of a high quality.

\section{Method}

Senior managers and clinicians (box 2) from four selected purchaser-provider pairings in the former Northern Region were invited to participate in a previously piloted semistructured interview. Sites were purposively selected on the basis of local knowledge on the progress of clinical audit to maximise the chance of obtaining informed views from those sites where audit seemed to be progressing well, based upon the annual reporting and review mechanisms of the Northern Regional Health Authority. The provider sites included one acute hospital and three combined acute and community care organisations.

Interviewees capable of providing an informed perception were identifed by discussion with knowledgeable local opinion leaders who had a considerable understanding of audit. This discussion included questions such as "To whom should I talk, to enrich my present understanding?" and "Who is likely to hold a different view?" This process identified the roles held by those considered to be most likely to inform the study.

To minimise the potential for interviewer variation, interviews were conducted by a single interviewer (CE) between March and November 1993 and lasted from 40 to 90 minutes. The content of the semistructured interviews was developed through discussion within the study team and drew upon other expert opinion in the published literature. The interviewer used a semistructured interview to
- Perceptions of clinical audit: definitions, purpose, progress, and expectations

- The impact of the internal health care market and involvement of purchasers

- The influence of clinical audit on purchaserprovider relation

- Sharing clinical audit information

- The integration of clinical audit into the contracting process

- The future funding to support audit

- Critical success factors likely to be of benefit in determining the way forward

Box 3 Content of the semistructured interview

ensure that the same seven areas were discussed in each interview, but within each area there was considerable flexibility to allow interviewees to expand upon particular issues and for the interviewer to probe further (box 3 ). A series of questions, probes, and prompts were developed, based on informed judgement or theoretical knowledge, which formed a written guide for the interviews. To enhance validity different types of questions were asked concurrently. ${ }^{15}$ Care was also taken in framing the questions to avoid influencing the interviewees' answers through the use of influential or subjective language. To improve the validity of the data collected, three criteria modified from those suggested by Kunzel and Like ${ }^{16}$ have been used: (1) Triangulation, using multiple interviewees who occupy the same role in similar organisations.

(2) The inclusion of conflicting as well as complementary data.

(3) Recycling information back to the interviewee for verification.

Interviews were recorded on to audiotape and transcribed. Each interviewee was provided with a written summary of their interview within two weeks to check the accuracy and completeness of the interviewer's understanding.

The qualitative data obtained in the semistructured interviews were subjected to content analysis ${ }^{15}$ which provided an analytical framework to allow the indentification of, and comparison between, eminent themes and concepts. Qualitative techniques were used to discover relations, patterns, and associations based on the personal experience of interviewees in relation to the research objectives previously identified (figure).

This involved developing a rudimentary set of criteria based on existing theoretical understanding, which was expanded through a systematic review of the transcribed text to identify keywords, phrases, and themes. No subsequent changes were made to the expanded criteria during the coding stage.

\section{Results}

Forty two (93\%) of the 45 invited participants were interviewed; results are presented within each of the seven specific areas included in the

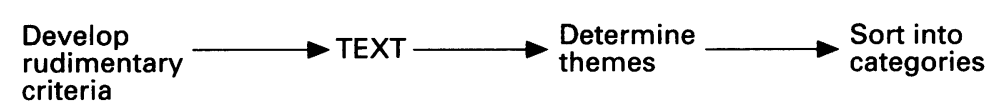


semistructured interview, alongside illustrative quotes.

PERCEPTIONS OF CLINICAL AUDIT: DEFINITION, PURPOSE, PROGRESS, AND EXPECTATIONS

The definitions and purposes of clinical audit suggested by both groups of interviewees were very similar. Both purchasers and providers saw the role of clinical audit as measuring and improving the quality of patient care and evaluating practice. However, purchasers placed greater emphasis on the need for the process to show outcome, effectiveness, efficiency, and value for money. Conversely, providers were more likely to emphasise the educational role and the ability to produce change. Of interest, non-clinical interviewees were more likely to mention the continuous cyclical process of clinical audit.

"I see audit as an educational activity. I don't think purchasers see it this way, to them it's more about cost and I don't think the two go together." (consultant, provider)

Both purchasers and providers thought that progress in clinical audit had initially been slow but was now improving, albeit with variation across specialties. However, some purchasers felt excluded from clinical audit and unable to provide an informed judgement.

"I find it difficult to judge the value of audit as I've felt very detached from the process." (contracting leader, purchaser)

Purchasers were also concerned that clinical audit was focused on the process rather than the outcome.

Views expressed about the future of clinical audit were wide and varied, although most thought that audit was now here to stay. Both purchasers and providers commonly mentioned the multidisciplinary development of clinical audit and the need to consider the primary-secondary care interface.

Views expressed on how the goals of clinical audit would be achieved in the future differed between purchasers and providers. Providers thought that for clinical audit to achieve its purposes, more protected time, information technology, support staff, and money would be needed. They also emphasised the need for cultural change, for a multidisciplinary approach, and for obvious benefits. These views were not commonly expressed by purchasers.

"We need protected time, and more support staff, the problem is meeting clinical commitments, and still finding the time for audit, especially as I am now the clinical director and also have to spend more time on management." (consultant, provider)

There was a consensus of opinion among provider interviewees that audit will become integrated into the quality processes of their organisation, possibly because they recognise that the provision of services which are of known high quality will not only benefit patients, but may represent competitive opportunities. Interviewees from purchasing organisations have a somewhat different future agenda, expressing the view that audit will develop to become a means of showing outcome and efficiency, reflecting their purchasing priorities.

IMPACT OF THE INTERNAL HEALTHCARE

MARKET AND INVOLVEMENT OF PURCHASERS

Both purchasers and providers thought that the considerations for clinical audit are at present driven by professional interests. Purchasers were particularly conscious of this, identifying that clinical audit topics reflect the considerations of providers. Both purchasers and providers thought that purchasers would exert a greater influence on the selection of topics for clinical audit in the future.

It was recognised that purchasers would become more involved in clinical audit, including the integration within contracts, but this engendered mixed views ranging from enthusiasm, through stoical acceptance, to open resistance. Purchasers thought that clinical audit could play an important part in meeting their requirements for provider performance data.

Some purchasers suggested that it was their responsibility to ensure that the performance of individual clinicians in the provider organisations with whom they held contracts was of a satisfactory standard. However, this responsibility was disputed by interviewees from provider organisations, particularly chief executives. These conflicting views may reflect the adjustments that need to be made in the light of the strategic shift in power as health authority chief executives move from managing health services, to managing health, and the managerial responsibility for consultants moves from regional health authorities, to become the responsibility of chief executives of the trusts.

"Consultant performance is an issue that will be dealt with as part of the internal management arrangements within the trust, otherwise where is the boundary between the district health authority acting as a purchaser and going back to managing the service?" (chief executive, provider)

"I object to purchasers dictating medical audit processes, and what to audit. In the same way that customers are not able to influence the quality assurance mechanisms in supermarkets, they just buy good quality products at competitive prices."

(consultant, provider)

Some interviewees thought that, as doctors become more involved in the managerial functions of the organisation, they will recognise the potential for audit to influence business issues. This view was particularly prevalent among interviewees from a hospital which operates a clinical directorate model.

Most interviewees agreed that the choice of audit topics has, until now, lacked strategic direction, being provider driven and reflecting predominantly professional interests. However, interviewees from one trust identified that their audit programme had been influenced by national priorities such as Health of the Nation targets and Patient's Charter standards. The 
way in which audit topics will be chosen in the future generated considerable diversity of opinion. Purchasers expressed the view that they would become much more involved in the selection of audit topics, ensuring that they are influenced significantly by the purchasing priorities previously identified.

"What must happen in the future is that audit topics must reflect the health priorities of the population, the purchaser will have a major role to play in this process."

(chief executive, purchaser)

Many providers were, however, sceptical about the ability of purchasers to appropriately influence the choice of audit topics. Doubts were voiced about how the process will work and concern expressed that clinical ownership will be diminished.

"Ownership is vital, there are problems if standards are set externally or hierarchically."

(fundholding general practitioner)

Some support was expressed for the approach identified in central guidance, ${ }^{7}$ which suggests that it is possible for purchasers and providers to collaborate to inform and develop the audit process. Such an approach will involve agreeing mutually acceptable considerations about audit which satisfy purchasers' requirements, but maintain a degree of clinical ownership. However, for this to be achieved clinicians will need to become more involved in discussion with purchasers.

INFLUENCE OF CLINICAL AUDIT ON THE RELATION BETWEEN PURCHASER AND PROVIDER Only nine subjects cited examples of clinical audit which they thought had influenced local purchasing decisions. These included the results of clinical audit being used to support the case for development of a service, production of guidelines for purchasing infertility treatment based upon outcome measures, and new contracting arrangements allowing general practitioner fundholders to have direct access to some secondary care services. Most thought that no such impact had occurred, but that it was probably still too early.

Provider clinicians expressed concern about the lack of involvement of clinicians in discussions with purchasers. Purchasers were more likely to think that clinical audit would have an influence in the future on purchasing decisions, although some providers saw opportunities for clinical audit to influence purchasing decisions.

"Audit results will enable me to demonstrate to the purchaser that it is not appropriate to undertake some surgical procedures as a day-case, because it can put patients at risk. As a doctor I already know this, but audit will enable me to prove it to others." (audit committee chair, provider)

SHARING INFORMATION ON CLINICAL AUDIT Most of the interviewees stated that the audit annual report was, at the time, the primary means by which information on clinical audit was shared between purchasers and providers. Purchasers tended to think that this information was too limited. However, three out of four provider organisations had a public health doctor on their audit committee, representing the purchaser as well as their own specialty interest.

A third of both purchasers and providers thought that only the conclusions of clinical audit should be shared, and there was wide agreement that the identity of individual patients should not be divulged. Clinicians strongly asserted that clinical audit should be made anonymous and providers were more likely than purchasers to assert that the identity of individual clinicians should remain confidential. In contrast to providers, purchasers did not identify that a barrier to the audit process may occur if results are used punitively.

"Some doctors take the view that no one may question their practice, which is a complete anathema to modern management techniques. I have no qualms about professionals being told they are not coming up to standard."

(chief executive, purchaser)

"I can't think of any information we would want to share, audit is confidential to the doctors who carry it out."

(audit committee chair, provider)

Non-clinical informants were particularly sensitive about the lack of willingness among clinicians to share clinical information with non-clinicians, citing the example that their public health colleagues were privy to data which were withheld from them.

INTEGRATION OF CLINICAL AUDIT INTO THE CONTRACTING PROCESS

Purchasers were more aware than providers of the inclusion of clinical audit in quality specifications in contracts, especially the requirements to undertake audit that currently exist. Purchasers thought that clinical audit would influence quality specifications in contracts in the future to a greater extent and that contracts would become more detailed and specific, including the specification of audit standards.

Providers were less likely to think that clinical audit and contracting would become integrated and hence influence, for example, contract placement and general practitioners' referral patterns.

"I don't think audit has any part to play in the contracting arrangements, it is a professional issue." (consultant, provider)

"I don't know how purchasers could specify audit in contracts in any detail as they are so remote from what we do."

(audit committee chair, provider)

"Purchasers will define specific requirements for audit in contracts. This is part of the learning curve for clinicians, but they are 
increasingly awakening to the real world, recognising that ' $\mathrm{He}$ who pays the piper, calls the tune'." (chief executive, provider) "The education of purchasers is paramount if inappropriate comparisons are to be avoided."

(consultant, provider)

"Purchasers will not place contracts with providers without knowledge of their performance, in this way audit will influence contract placement."

(contracting leader, purchasing)

EXPECTATIONS FOR THE FUTURE FUNDING OF CLINICAL AUDIT

Purchasers expressed the view more strongly than providers that resources should be linked to the effectiveness of clinical audit and the requirement for purchasers to approve the clinical audit programme. The most commonly held view was that the costs of clinical audit should become part of the contract price. Some interviewees suggested that there needs to be a mechanism to ensure that the money remains protected for the purpose for which it was intended. A few providers thought that the funding should continue to be "ring fenced" thus bypassing purchasers, a view not supported by any purchasers.

"I think there needs to be a mechanism to ensure that the money to support audit is not stolen for other purposes."

(consultant, provider)

Many purchasers suggested that they will expect to agree the future audit programme with providers before funding is released, thus recognising that the changes to funding arrangements of audit will enable them to exert more control over the process.

"Purchasers will negotiate with their providers and agree how the money will be spent, this will give purchasers a degree of ownership and ensure that providers have to account for what they do."

(chief executive, purchaser)

OTHER IMPORTANT FACTORS

By this stage of the interview most of the issues had been covered and few interviewees were able to add further factors to those already discussed. Both purchasers and providers emphasised the need for mutual dialogue. Interviewees suggested a range of ideas to promote successful interaction between purchasers and providers on clinical audit: the most commonly expressed requirements being constructive dialogue between the two groups, trust, and a common understanding of the process coupled with realistic expectations. Doctors in particular expressed concern about their lack of involvement in the negotiation of contracts for services.

\section{Discussion}

This study used semistructured interviews to seek views on the purchaser-provider interaction and clinical audit from key staff with an interest in, or influence on, the future progress of audit. The study was limited to four purposively chosen fieldwork sites, the selection of which was influenced by the provider organisations showing, through their annual reports, that audit was well established within their services. Although this selection criterion ensured that the sites were data sources rich in information, they cannot be deemed to be representative, as there is bias in the data towards organisations that have taken a positive approach to audit. Furthermore, identification of those most likely to be able to inform the study at this stage of the development of audit resulted in a predominance of doctors representing the clinical view, possibly due to the emphasis that had been placed up to then on medical audit rather than clinical audit. None the less, the nursing perspective was represented, although the professions allied to medicine were not. These potential biases should be kept in mind in interpreting the findings of the research and drawing conclusions from them. ${ }^{15}$

These views are likely to be of benefit in influencing the evolving relations between purchasers and providers on clinical audit. The results have highlighted areas in which there is a common perception, and also areas in which disparate views could potentially create tensions between purchasers and providers.

It was not the intention of the study to explore differences between medical and managerial opinions, but rather to concentrate on the broader perspectives of purchasers and providers. Shared views between purchasers and providers were found in several areas. Thus, it is encouraging to see that there is a common perception of the primary purpose of clinical audit in terms of improving the quality of patient care. However, it is perhaps not surprising that purchasers may put a greater premium on the role of clinical audit in externally evaluating practice. This suggests that purchasers are concerned to see a greater impact of the programme and greater potential to influence purchasing decisions. Providers are interested in seeing improvements in patient care as an end point, whereas purchasers may think that if clinical audit is to be of value to them, it needs to enable them to identify where good (and bad) practice occurs. Purchasers think that they need more than reassurance that clinical audit can or does lead to an improved quality of patient care from providers, and that it should begin to influence purchaser-provider interaction and purchasing decisions.

Issues cited as mitigating the progress of clinical audit included obstacles reported by other authors, such as the sensitivity of doctors to review of their performance, the protection of professional autonomy and a reluctance to judge peers, inadequate data and information systems, lack of time, and suspicion about the interests of managers and purchasers in clinical audit. ${ }^{1012} 1718$

"There is a temptation for managers and purchasers to marry audit with discipline, this is very short sighted as it will be the end of honest medical audit."

(consultant, provider) 
These differences at least partly reflect the differing organisational aims of purchasers and providers. None the less, given the level of agreement on the ultimate purpose of audit between them, these differences suggest that a greater understanding and dialogue is required between purchasers and providers if conflict is to be avoided and clinical audit is to be advanced. The approach of some purchasers may be counter productive if the expressed concerns of providers are not acknowledged. This raises issues of the most appropriate relation between purchasers and providers for quality improvement. Such a relation may range from antagonistic to cooperative. Trying to impose widely different views may lead to a more antagonistic model, which may then undermine the effectiveness of the purchaserprovider interaction. ${ }^{19}$

Many of the views expressed by purchasers indicate their detachment from the process of providers' clinical audit, perceived to be due, at least in part, to the historical flow of funds from regional health authorities to providers, with regional health authorities taking the lead role in monitoring progress. Our findings suggest that purchasers are keen to see and support further development of clinical audit, but wish to be more involved. A protectionist approach by providers is unlikely to foster constructive involvement of purchasers.

Indeed, providers recognised that purchasers might be ill informed. Our study suggests that this may indeed be the case and that the recognition of the need for greater dialogue is the most fertile means of (if not harmonising views) at least enhancing awareness of and respect for each other's perspectives.

There was a mutual recognition that in the future clinical audit will involve more clinical disciplines working together and will become more closely integrated with other quality initiatives. Furthermore, both purchasers and providers expressed the view that the purchaser role would increase, although with mixed views as to whether that would be either desirable or effective. Doctors who also have key managerial responsibilities - for example, clinical directors - seemed to be more positive towards clinical audit becoming integrated with contracting and service development, and reflecting national and local priorities (including those of the purchaser).

Providers tended to be sceptical about the ability of purchasers to appropriately influence the selection of priorities for clinical audit. This may in part reflect the knowledge of the importance of ownership as a lever for change, ${ }^{20}$ but at the time of the study this was more an imagined than real effect, purchasers to date having had minimal influence.

It is clear from this study that the influence of the purchaser-provider interaction on the clinical audit programme has been limited. This reflects several features, including the recognised and again expressed view about the lack of clinical involvement in contracting. ${ }^{21} \mathrm{It}$ would seem important, given what we know about the role of ownership in clinical audit, that clinicians should have some feeling of ownership for contracts relevant to clinical audit. Even when clinical audit was included in contracts, this would seem to have had little impact. Others have reported that contracts for clinical audit, when they existed at that time, were highly variable in terms of their structure, scope, and content. ${ }^{13}$

Even in the case of the progressive Northern Region sites selected in our study, clinical audit has had little apparent impact in influencing purchasing or service development. This is perhaps not surprising given the limited exchange of dialogue and information. Indeed, purchasers received little more than very general annual reports and some felt excluded from the clinical audit programmes. This leads on to the issue of consensus about the confidentiality of data and information on clinical audit. Without a mature dialogue it is perhaps not surprising that providers have major concerns about including detailed results of clinical audit within the largely paper records passing to purchasers. None the less, purchasers themselves recognise these sensitivities and would seem to be amenable to discussion on the details of information flow. For purchasers to be able to make informed judgements on clinical audit, it is essential that agreements on exchange of information are reached.

So what are the key messages for the future? Clearly, clinical audit is thought to be here to stay and there is a recognitition that the role and impact of purchasers will increase. However, this recognition must be tempered with concerns based around differing perceptions and expectations of purchasers and providers. None the less, it seems that much of this difference of opinion has not been tested by purchaser-provider dialogue. It may be that the bypassing of the purchaser in the early days of the national audit programme may have contributed to purchasers who are poorly informed and who are now very keen to have an influence that they have to date lacked. As a result, the main conclusion from this study is of a clear need for enhanced dialogue. Control of funding of clinical audit by purchasers will inevitably force this debate into the open. Purchasers must, however, recognise the fears and anxieties that this change is generating within providers; purchasers must be sensitive to the detrimental effect that attempts to direct clinical audit from outside might have.

It is too early for clinical audit to have made a major impact on the purchaser-provider interaction, but it is clear that the purchaserprovider interaction is beginning to make an impact on clinical audit. The interaction needs to be as far as possible open and based on trust and sharing of perspectives. The results of this study support the message coming from the private sector that purchasing is about managing relationships, not about buying things. The planned clinical audit programme should be mutually agreed with the value of audit requested by purchasers being understood and accepted. Clinical audit will best prosper if it takes place within a climate of trust and mutual professional respect. The 
structural mechanisms to support this need to be created - for example, by the creation of purchaser-provider audit groups to develop an understanding of the short term needs of audit and to enable a more strategic approach to the setting and agreement of priorities in audit such that they begin to meet the aspirations of both purchasers and providers.

We thank Bill Ennis and John Woodhouse for their helpful comments and support in the development of this project, the Northern Regional Health Authority for funding, and the interviewees who gave so freely of their time.

1 NHS and Community Care Act. London: HMSO, 1990

2 Hopkins A, Maxwell R. Contracts and quality of care. BMF 1990;300:919-2

3 Department of Health. Contracts for health services: operational principles. London: HMSO, 1989.

4 Department of Health. Funding and contracts for hospital services: working paper 2 London: HMSO, 1989.

5 Department of Health. Working for patients. Working paper 6: medical audit. London: HMSO, 1989.

6 Department of Health. Clinical audit: meeting and improving standards in health care. London: HMSO, 1993.

7 Thomson RG, Cook G, Lelliot P, Baker I, Godwin R. Audit and the purchaser-provider interaction. London: Department of Health, 1993. (EL(93)34. Annex B.)

8 Department of Health. Clinical audit initiative: funding for 1994/5 and beyond. London: HMSO, 1993. (EL(93)104.)
9 Harman D, Martin G. Medical audit and the manager Birmingham: Health Services Management Centre, 1991

10 Black N, Thompson E. Obstacles to medical audit: British doctors speak. Soc Sci Med 1993;6:849-56.

11 Thomson RG Barton AG. Is audit running out of steam? Quality in Health Care 1994;3:225-9.

12 Smith HE, Russell GI, Frew AJ, Dawes PT. Medical audit: the differing perspectives of managers and clinicians. $\mathcal{F} R$ Coll Physicians Lond 1992;26:177-80.

13 Rumsey M, Walshe K, Coles J, Bennett J. The role of the commissioner in audit: findings of a national survey of Research, 1994

14 Buttery Y, Walshe K, Coles J, Bennett J. The development of audit: findings of a national survey of healthcare provider units in England. London: CASPE Research, 1994.

15 Crabtree BF, Miller WL. The analysis of narratives from long interview. In: Stewart $M$, et al., eds. Tools for primary care research. London: Sage, 1992:209-22.

16 Kunzel AJ, Like RC. Standards of trustworthiness for qualitative studies in primary care. In: Norton $P$, ed. Primary care research: traditional and innovative approaches. London: Sage, 1991:138-58.

17 Cook G. Purchasers views on the medical audit programme. North Western Regional Health Authority, 1992.

18 Gumpert $\mathrm{R}$, Lyons $\mathrm{C}$. Setting up a district audit programme. BMF 1990;301:162-5.

19 Thomson RG. The purchaser role in provider quality: lessons from the United States. Quality in Health Care 1994;3:65-6.

20 Grimshaw JN, Russell IT. Achieving health gain through clinical guidelines: II Ensuring that guidelines change medical practice. Quality in Health Care 1994;3:45-52.

21 Bensley D, Bull A, Haward R. Consultants' involvement in the contracting process in the Yorkshire Region. BMF $1991 ; 305: 95$ 